\title{
Effects of dietary incorporation of linseed oil with soybean isoflavone on fatty acid profiles and lipid metabolism-related gene expression in breast muscle of chickens
}

\author{
Z. Y. Gou* ${ }^{*}$ X. Y. Cui* ${ }^{\star}$, L. Li, Q. L. Fan, X. J. Lin, Y. B. Wang, Z. Y. Jiang and S. Q. Jiang ${ }^{\dagger}$ \\ Institute of Animal Science, Guangdong Academy of Agricultural Sciences, State Key Laboratory of Livestock and Poultry Breeding, Key Laboratory of Animal Nutrition and \\ Feed Science in South China, Ministry of Agriculture and Rural Affairs, Guangdong Key Laboratory of Animal Breeding and Nutrition, Guangzhou 510640, China
}

(Received 13 October 2019; Accepted 16 April 2020; First published online 19 May 2020)

The meat quality of chicken is an important factor affecting the consumer's health. It was hypothesized that $n-3$ polyunsaturated fatty acid (n-3 PUFA) could be effectively deposited in chicken, by incorporating antioxidation of soybean isoflavone (SI), which led to improved quality of chicken meat for good health of human beings. Effects of partial or complete dietary substitution of lard (LA) with linseed oil (LO), with or without SI on growth performance, biochemical indicators, meat quality, fatty acid profiles, lipid-related health indicators and gene expression of breast muscle were examined in chickens. A total of 900 males were fed a corn-soybean meal diet supplemented with $4 \% L A, 2 \% L A+2 \% L O$ and $4 \% L O$ and the latter two including $30 \mathrm{mg}$ $S I / k g(2 \% L A+2 \% L O+S I$ and $4 \% L O+S I)$ from 29 to 66 days of age; each of the five dietary treatments included six replicates of 30 birds. Compared with the $4 \%$ LA diet, dietary $4 \%$ LO significantly increased the feed efficiency and had no negative effect on objective indices related to meat quality; $L O$ significantly decreased plasma triglycerides and total cholesterol (TCH); abdominal fat percentage was significantly decreased in birds fed the $4 \% L O$ and $4 \% L O+S I$ diets. Chickens with LO diets resulted in higher contents of $\alpha$-linolenic acid (C18:3n-3), EPA (C20:5n-3) and total n-3 PUFA, together with a lower content of palmitic acid (C16:0), lignoceric acid (C24:0), saturated fatty acids and n-6:n-3 ratio in breast muscle compared to 4\% LA diet ( $\mathrm{P}<0.05)$; they also significantly decreased atherogenic index, thrombogenic index and increased the hypocholesterolemic to hypercholesterolemic ratio. Adding SI to the LO diets enhanced the contents of EPA and DHA (C22:6n-3), plasma total superoxide dismutase, reduced glutathione (GSH)/oxidized glutathione and muscle GSH content, while decreased plasma total triglyceride and TCH and malondialdehyde content in plasma and breast muscle compared to its absence $(\mathrm{P}<0.05)$. Expression in breast muscle of fatty acid desaturase 1 (FADS1), FADS2, elongase 2 (ELOVL2) and ELOVL5 genes were significantly higher with the LO diets including SI than with the 4\% LA diet. Significant interactions existed between LO level and inclusion of SI on EPA and $T C H$ contents. These findings indicate that diet supplemented with $L O$ combined with $S I$ is an effective alternative when optimizing the nutritional value of chicken meat for human consumers.

Keywords: growth performance, n-3 polyunsaturated fatty acid, meat quality, antioxidation, health indicator

\section{Implications}

Dietary linseed oil can increase the content of $n-3$ polyunsaturated fatty acid in chicken meat, this effect being potentially increased with soybean isoflavone which has strong antioxidant activity. Indeed, dietary linseed oil improves tissue fatty acid profiles and, when distributed with $\mathrm{SI}$, increases the proportion of long chain $\mathrm{n}-3$ polyunsaturated fatty acid in meat and levels of indicators of antioxidant status in muscle and plasma of chicken. These

\footnotetext{
*The first two authors contributed equally to this work.

${ }^{\dagger}$ E-mail: jsqun3100@hotmail.com
}

dietary strategies are effective methods to improve the nutritional value of chicken meat.

\section{Introduction}

Chicken is a major source of meat, which is popular with consumers all over the world. The nutritional quality of chicken meat is a significant factor affecting the consumer's health. The $n-3$ polyunsaturated fatty acid (PUFA) in human nutrition have drawn considerable interest due to their potential health benefits, such as contributing to the development 
of infant brain and decrease in the risk of tumors, cardiovascular diseases, and inflammatory disorders (Ruxton et al., 2007; Riediger et al., 2009). The most significant n-3 PUFAs are $\alpha$-linolenic acid (ALA, C18:3n-3), EPA (C20:5n-3) and DHA (C22:6n-3). Importantly, ALA serves as a precursor of other n-3 long-chain fatty acids such as EPA and DHA (Rymer and Givens, 2005). The nutritional profile of meat products can be improved by replacing saturated fatty acids (SFAs) with n-3 PUFA in animal diets. Linseed oil (LO) is the most commonly used nutritional lipid source for its high content of ALA, and supplementation of the chicken diet with LO can increase the content of n-3 PUFA in chicken meat products (Kartikasari et al., 2012). The potential for unsaturated fatty acids, especially the n-3 PUFA, to undergo deleterious oxidation can be offset by simultaneous inclusion of antioxidants in the diet (Kouba and Mourot, 2011). Soybean isoflavones (SIs), as phenolic compounds including genistein, daidzein and glycitein, are the main phytoestrogens of soybeans (Setchell, 1998). The SIs have strong antioxidant activity in vivo and in vitro (Liu et al., 2005; Jiang et al., 2007a) and their dietary inclusion improve growth performance and meat quality by decreasing lipid peroxidation and improving antioxidative status in broiler chickens (Jiang et al., 2007b; Jiang et al., 2014).

In the present study, the lard (LA)-containing basal diet of chickens was modified by substituting half or all of the LA with LO, with or without an effective quantity of SI. The objective was to assess the effects of such dietary regimens on the growth performance, biochemical indicators, meat quality, fatty acid profiles, lipid-related health indicators and expression of genes related to lipid metabolism in the breast muscle of chickens.

\section{Material and methods}

\section{Birds, diets and experimental design}

A total of 900 1-day-old fast-growing Chinese yellow-feathered male chicks (Lingnan, an improved meat-type breed with good meat quality that is popular locally) were obtained from Guangdong Wiz Agricultural Science and Technology Co. Ltd. (Guangzhou, China). All birds were fed a standard starter diet from 1 to 29 days of age. They were weighed at day 29 (BW and SEM $597 \pm 2.00 \mathrm{~g}$ ) and randomly allotted to a total of 30 floor pens $(1.3 \mathrm{~m} \times 3.5 \mathrm{~m})$ in an environmentally controlled room for the 37-day experiment during the grower and finisher phases (day 29 to 66). Pens were then randomly assigned to the five dietary treatments, each of which included six replicates of 30 birds. The control group was fed a basal diet containing 4\% LA and the four treatment diets received the basal diet modified as follows: $2 \%$ $\mathrm{LA}+2 \% \mathrm{LO} ; 4 \% \mathrm{LO}$; or the latter two diets containing $30 \mathrm{mg} \mathrm{SI} / \mathrm{kg}(2 \% \mathrm{LA}+2 \% \mathrm{LO}+\mathrm{SI}$ and $4 \% \mathrm{LO}+\mathrm{SI})$. The $\mathrm{SI}$ was from Newlands Feed Science and Technology, Guangzhou, China. Experimental diets were formulated based on the Chinese Feeding Standard of Chicken published in 2004 and the Feed Database in China in 2018. The first three diets are described in Table 1, and the SI was added to the premix used for the last two. The fatty acid composition of diets is presented in Table 2. Feed and water for consumption were provided ad libitum. Mortality of birds was recorded daily. At day 66 (typical market age), the birds were deprived of feed for $12 \mathrm{~h}$ and reweighed to calculate the average daily gain (ADG). Average daily feed intake (ADFI) was recorded on a replicate basis and the feed/gain ratios were calculated.

\section{Sample collection}

Birds were sampled on day 66 . Following the 12 -h overnight fast, 12 chickens per treatment (two birds per replicate) with BW close to the replicate average were chosen. Heparinized blood samples were collected from the brachial vein; plasma samples were separated by centrifugation of blood at $1200 \times \mathrm{g}$ for $10 \mathrm{~min}$ at $4^{\circ} \mathrm{C}$ and plasma aliquots were kept at $-80^{\circ} \mathrm{C}$. The birds were then electrically stunned and exsanguinated before obtaining the tissues. The dressed weight was recorded; breast muscle was quickly sampled from the same area on the right side, snap frozen in liquid nitrogen and stored at $-80^{\circ} \mathrm{C}$ for RNA extraction and biochemical analysis. The remaining breast muscle from the right side was used to measure the intramuscular fat (IMF) content and fatty acid analysis, and the left breast muscle was used for the determination of meat quality indicators. Abdominal fat was removed and weighed, and the abdominal fat percentage was calculated (abdominal fat weight as a percentage of dressed weight).

\section{Biochemical analysis}

Frozen muscle tissues of $40 \mathrm{mg}$ in $4 \mathrm{ml}$ of homogenization buffer (0.05 M Tris-HCl, pH 7.4, 1 mM EDTA, 0.25 M sucrose) were homogenized on ice with an Ultra-Turrax (T8; IKALabortechnik, Staufen, Germany) for $5 \mathrm{~s}$ at $13500 \mathrm{rpm}$. The homogenate was centrifuged at $12000 \times \mathbf{g}$ for $10 \mathrm{~min}$ at $4^{\circ} \mathrm{C}$ and the supernatant was stored at $-80^{\circ} \mathrm{C}$. The activity of total superoxide dismutase (T-SOD) and the contents of total antioxidant capacity (T-AOC), reduced glutathione (GSH), oxidized glutathione (GSSG) and malondialdehyde (MDA) were determined using colorimetric methods to measure thiobarbituric acid reacting substances with a spectrophotometer (Biomate 5; Thermo Electron Corporation, Rochester, NY, USA). The assays were conducted with the kits purchased from Nanjing Jiancheng Institute of Bioengineering (Nanjing, Jiangsu, China) following the manufacturer's procedures. The GSH/GSSG ratio was subsequently calculated. The plasma concentrations of total triglyceride (TG), total cholesterol (TCH), high-density lipoprotein cholesterol (HDL-C) and low-density lipoprotein cholesterol (LDL-C) were measured by an autoanalyzer (Selectra ProXL Clinical Chemistry System, the Netherlands) using commercial kits (Biosino Bio-technology and Science Inc., Beijing, China).

\section{Meat quality measurements}

Samples of left pectoral muscle were used to measure the color, pH, drip loss and shear force. Meat color was measured 
Gou, Cui, Li, Fan, Lin, Wang, Jiang and Jiang

Table 1 Composition and nutrient levels of experimental diets of yellow-feathered chickens from 29 to 66 days of age (\% as fed basis)

\begin{tabular}{|c|c|c|c|c|c|c|}
\hline \multirow[b]{2}{*}{ Components } & \multicolumn{3}{|c|}{29 to 49 days } & \multicolumn{3}{|c|}{50 to 66 days } \\
\hline & $4 \% \mathrm{LA}$ & $\begin{array}{l}2 \% \mathrm{LA}+2 \% \mathrm{LO} \\
\text { (with or without SI) }\end{array}$ & $\begin{array}{c}4 \% \text { LO } \\
\text { (with or without SI) }\end{array}$ & $4 \% \mathrm{LA}$ & $\begin{array}{l}2 \% \mathrm{LA}+2 \% \mathrm{LO} \\
\text { (with or without SI) }\end{array}$ & $\begin{array}{c}4 \% \text { LO } \\
\text { (with or without SI) }\end{array}$ \\
\hline \multicolumn{7}{|l|}{ Ingredient (\%) } \\
\hline Corn & 61.8 & 61.8 & 61.8 & 65.7 & 65.7 & 65.7 \\
\hline Soybean meal & 26.3 & 26.3 & 26.3 & 19.1 & 19.1 & 19.1 \\
\hline Corn gluten meal & 3.0 & 3.0 & 3.0 & 4.0 & 4.0 & 4.0 \\
\hline Lard & 4.0 & 2.0 & 0 & 4.0 & 2.0 & 0 \\
\hline Linseed oil & 0 & 2.0 & 4.0 & 0 & 2.0 & 4.0 \\
\hline L-Lysine $\mathrm{HCl}$ & 0.13 & 0.13 & 0.13 & 0.14 & 0.14 & 0.14 \\
\hline DL-Methionine & 0.11 & 0.11 & 0.11 & 0.13 & 0.13 & 0.13 \\
\hline Limestone & 1.11 & 1.11 & 1.11 & 1.12 & 1.12 & 1.12 \\
\hline Dicalcium phosphate & 1.73 & 1.73 & 1.73 & 1.58 & 1.58 & 1.58 \\
\hline Salt & 0.26 & 0.26 & 0.26 & 0.26 & 0.26 & 0.26 \\
\hline Zeolite powder & 0.56 & 0.56 & 0.56 & 2.97 & 2.97 & 2.97 \\
\hline Premix ${ }^{1}$ & 1.00 & 1.00 & 1.00 & 1.00 & 1.00 & 1.00 \\
\hline Total & 100.00 & 100.00 & 100.00 & 100.00 & 100.00 & 100.00 \\
\hline \multicolumn{7}{|l|}{ Nutrient composition ${ }^{2}$} \\
\hline Metabolizable energy (MJ/kg) & 13.09 & 13.04 & 12.98 & 13.10 & 13.04 & 12.99 \\
\hline $\mathrm{CP}(\%)$ & 19.02 & 19.02 & 19.02 & 17.02 & 17.02 & 17.02 \\
\hline Crude fat $(\%)$ & 6.89 & 6.89 & 6.89 & 6.87 & 6.87 & 6.87 \\
\hline Lysine $(\%)$ & 1.00 & 1.00 & 1.00 & 0.85 & 0.85 & 0.85 \\
\hline Methionine (\%) & 0.41 & 0.41 & 0.41 & 0.41 & 0.41 & 0.41 \\
\hline Methionine + cysteine (\%) & 0.71 & 0.71 & 0.71 & 0.69 & 0.69 & 0.69 \\
\hline Calcium (\%) & 0.90 & 0.90 & 0.90 & 0.85 & 0.85 & 0.85 \\
\hline Non-phytate phosphorus (\%) & 0.40 & 0.40 & 0.40 & 0.37 & 0.37 & 0.37 \\
\hline
\end{tabular}

$\mathrm{LA}=$ lard; $\mathrm{LO}=$ linseed oil; $\mathrm{SI}=30 \mathrm{mg} / \mathrm{kg}$ soybean isoflavone.

${ }^{1}$ Provided the following per kilogram of diet in two feeding stages, Vitamin $B_{1}, 2.4,2.1 \mathrm{mg}$; Vitamin $\mathrm{B}_{2}, 4,3 \mathrm{mg} ;$ niacin, 17, $15 \mathrm{mg}$ and choline chloride, $600,500 \mathrm{mg}$, separately; Vitamin A, $6000 \mathrm{IU}$; Vitamin $\mathrm{D}_{3}, 500 \mathrm{IU}$; Vitamin $\mathrm{E}$, $20 \mathrm{IU}$; Vitamin $\mathrm{K}_{3}, 0.50 \mathrm{mg}$; pantothenic acid, $10 \mathrm{mg}$; Vitamin $\mathrm{B}_{6}, 3.5 \mathrm{mg}$; biotin, $0.15 \mathrm{mg}$; folic acid, 0.55 , $\mathrm{mg}$; Vitamin $\mathrm{B}_{12}, 0.01 \mathrm{mg} ; \mathrm{Fe}, 80 \mathrm{mg} ; \mathrm{Cu}, 7 \mathrm{mg}$; Mn, $60 \mathrm{mg} ; \mathrm{Zn}, 75 \mathrm{mg} ; \mathrm{l}, 0.35 \mathrm{mg}$; Se, $0.23 \mathrm{mg}$.

${ }^{2}$ Values were calculated from data provided by Feed Database in China (2018).

Table 2 Fatty acid composition in the experimental diets of yellow-feathered chickens from 29 to 66 days of age

\begin{tabular}{|c|c|c|c|c|c|c|}
\hline \multirow[b]{2}{*}{ Fatty acid (\%) } & \multicolumn{3}{|c|}{29 to 49 days } & \multicolumn{3}{|c|}{50 to 66 days } \\
\hline & $4 \%$ LA & $2 \% \mathrm{LA}+2 \% \mathrm{LO}$ & $4 \%$ LO & $4 \%$ LA & $2 \% \mathrm{LA}+2 \% \mathrm{LO}$ & $4 \%$ LO \\
\hline C14: 0 & 0.83 & 0.46 & 0.12 & 0.82 & 0.47 & 0.13 \\
\hline C16: 0 & 18.55 & 13.52 & 8.64 & 18.51 & 13.52 & 8.65 \\
\hline C16: 1n-7 & 1.64 & 0.88 & 0.14 & 1.63 & 0.87 & 0.14 \\
\hline C18: 0 & 8.71 & 5.89 & 3.15 & 8.61 & 5.81 & 3.09 \\
\hline C18: 1n-9 & 34.83 & 27.80 & 20.95 & 34.90 & 27.89 & 21.04 \\
\hline $\mathrm{C} 18: 2 \mathrm{n}-6$ & 28.50 & 29.77 & 31.01 & 28.88 & 30.09 & 31.18 \\
\hline$C 18: 3 n-3$ & 1.42 & 16.54 & 31.24 & 1.30 & 16.25 & 30.67 \\
\hline $\mathrm{C} 20: 0$ & 0.91 & 0.90 & 0.76 & 0.95 & 0.91 & 0.84 \\
\hline C20 : 1n-9 & 0.81 & 0.79 & 0.77 & 0.83 & 0.77 & 0.81 \\
\hline$C 20: 4 n-6$ & 0.98 & 0.48 & 0.05 & 0.97 & 0.48 & 0.07 \\
\hline $\mathrm{C} 22: 0$ & 0.98 & 0.99 & 0.94 & 1.01 & 0.96 & 0.95 \\
\hline C24: 0 & 0.58 & 0.55 & 0.42 & 0.57 & 0.52 & 0.49 \\
\hline MUFA & 37.29 & 29.47 & 21.86 & 37.37 & 29.54 & 21.99 \\
\hline PUFA & 30.89 & 46.79 & 62.30 & 31.14 & 46.82 & 61.93 \\
\hline SFA & 30.55 & 22.30 & 14.04 & 30.47 & 22.19 & 14.17 \\
\hline
\end{tabular}

$\mathrm{LA}=$ lard; $\mathrm{LO}=$ linseed oil; MUFA = monounsaturated fatty acid; PUFA = polyunsaturated fatty acids; SFA = saturated fatty acid. 
at 45 min postmortem using a Chroma Meter to measure CIE $\mathrm{LAB}$ values $\left(L^{*}\right.$, relative lightness; $a^{*}$, relative redness, $b^{*}$, relative yellowness). The $\mathrm{pH}$ was measured at $24 \mathrm{~h}$ postmortem in the pectoralis major muscle with a portable $\mathrm{pH}$ meter equipped with an insertion glass electrode. The drip loss of breast muscle was estimated using the method described by Rasmussen and Andersson (1996); samples were placed in a plastic bag filled with air and fastened to avoid evaporation and held at $4^{\circ} \mathrm{C}$ for $24 \mathrm{~h}$, and the drip loss was determined by weighing. The shear force was determined using an Instron Universal Mechanical Machine (Instron model 4411; Instron Corp., Canton, MA, USA) as follows: after storage for $24 \mathrm{~h}$ at $4^{\circ} \mathrm{C}$, the samples were heated until the internal temperature was $75^{\circ} \mathrm{C}$. Samples $(1.0 \mathrm{~cm} \times$ $1.0 \mathrm{~cm} \times 2.5 \mathrm{~cm}$ ) were taken from each meat sample and sheared in triplicate perpendicular to the fiber orientation. The IMF content in the breast muscle was determined by extraction with petroleum ether in a Soxhlet apparatus. IMF is expressed as a percentage of the dry weight of the muscle.

\section{Fatty acid composition and analyses of lipid-related health indicators}

In preparation for the analysis of fatty acid composition, lipids from samples were extracted with diethyl ether/ petroleum ether (1:1, vol:vol) after being hydrolyzed. Fatty acid methyl esters (FAMEs) of total lipids were prepared for gas chromatographic determination by the Standard Determination of Fatty Acids in food in China (GB5009.168-2016). An Agilent 6890 gas chromatography system (Santa Clara, CA, USA) fitted with a TR-FAME chromatographic column $(100.0 \mathrm{~m} \times 250 \mu \mathrm{m} \times 0.20 \mu \mathrm{m})$ was used for separating and quantifying the FAME with internal standard (C11:0). The composition of the fatty acids is expressed as percentages of total fatty acids.

The lipid-related health indicators of breast muscle were estimated by the $n-6: n-3$ ratio and the following three indicators: atherogenic index (AI), thrombogenic index (TI) and hypocholesterolemic/hypercholesterolemic ratio $(\mathbf{h}: \mathbf{H})$. The $\mathrm{Al}$ and $\mathrm{TI}$ were calculated according to Ulbricht and Southgate (1991); $\mathrm{Al}=[\mathrm{C} 12: 0+(4 \times \mathrm{C} 14: 0)+\mathrm{C} 16: 0] /$ $[(\mathrm{PUFA})+($ monosaturated fatty acid, MUFA $)]$, and $\mathrm{TI}=[\mathrm{C} 14: 0+\mathrm{C} 16: 0+\mathrm{C} 18: 0] /[(0.5 \times$ MUFA $)+(0.5 \times$ $\mathrm{n}-6)+(3 \times n-3)+(\mathrm{n}-3 / \mathrm{n}-6)]$. The $\mathrm{h}: \mathrm{H}$ was calculated according to Fernández et al. (2007); $\mathrm{h}: \mathrm{H}=(\mathrm{C} 18: 1 \mathrm{n}-9+\mathrm{C} 18$ : $1 \mathrm{n}-7+\mathrm{C} 18: 2 \mathrm{n}-6+\mathrm{C} 18: 3 \mathrm{n}-6+\mathrm{C} 18: 3 \mathrm{n}-3+\mathrm{C} 20:$ $3 n-6+C 20: 4 n-6+C 20: 5 n-3+C 22: 4 n-6+C 22:$ $5 n-3+C 22: 6 n-3) /(C 14: 0+C 16: 0)$.

\section{RNA extraction and real-time quantitative $P C R$}

Total RNA was isolated from $100 \mathrm{mg}$ of frozen breast muscle using an extraction kit (Invitrogen, Carlsbad, CA, USA), according to the manufacturer's protocol. The concentration and purity of RNA were determined using a NanoDrop ND-1000 spectrophotometer (NanoDrop Technologies,
Wilmington, DE, USA). The OD260/280 values of all samples were limited to the range of 1.8 to 2.0. The RNA samples were reverse transcribed using M-MLV reverse transcriptase (Promega, Madison, WI, USA), and the specific primers (Supplementary Table S1) of nine genes were designed using Primer Premier 6.0 software, including fatty acid desaturase 1 (FADS1), FADS2, fatty acid elongase 2 (ELOVL2), ELOVL5, fatty acid synthase (FAS), lipoprotein lipase (LPL), 3-hydroxy-3-methylglutaryl-coenzyme A reductase $(H M G C R)$, carnitine palmitoyltransferase- $1 \alpha$ $(C P T 1 \alpha)$ and sterol regulatory element binding protein-1 (SREBP-1) genes.

The complementary DNA (CDNA) was amplified by quantitative PCR with a CFX96 Real-time System (Bio-Rad, Hercules, CA, USA) using an iTaq $^{\text {TM }}$ Universal SYBER ${ }^{\circledR}$ Green Supermix (Takara Biotechnology, Dalian, China). After initial denaturation for $3 \mathrm{~min}$ at $95^{\circ} \mathrm{C}$, amplification was performed for 39 cycles $\left(95^{\circ} \mathrm{C}\right.$ for $15 \mathrm{~s}, 30 \mathrm{~s}$ at the annealing temperature and $72^{\circ} \mathrm{C}$ for $30 \mathrm{~s}$ ). The specificity of the PCR products was evaluated by the analysis of melting curves. The comparative CT method was used to determine the fold changes in gene expression, with the fold change calculated as $2^{-\Delta \Delta C T}$. The results are expressed as the mean fold change in gene expression from triplicate analyses, using control group samples as the calibrators (arbitrarily assigned an expression level of 1 for each gene). Negative controls, without a cDNA template, were included in this experiment.

\section{Statistical analysis}

Replicate served as the experimental unit. All five diets were assessed using one-way ANOVA and, where appropriate, means were compared by Tukey tests. Values are reported as means \pm SEM derived from the error mean square for $n=6$. The few significant interactions between the level of LO substitution and addition of SI were examined by twoway GLM in SAS (version 9.1; SAS Institute, Cary, NC, USA), with exclusion of the basal diet; the remaining diets constitute a $2 \times 2$ factorial design. Differences were considered to be statistically significant at $P<0.05$.

\section{Results}

\section{Growth performance}

Compared to the $4 \%$ LA diet, substitution of half or all of the LA with LO significantly decreased the ADFI of chickens ( $2 \%$ or $4 \%$ LO v. $4 \%$ LA); the final BW and ADG of chickens from 29 to 66 days were not affected (Table 3 ).

\section{Indicators of lipid metabolism and antioxidation}

As shown in Table 4, there were no significant $(P>0.05)$ differences in the antioxidant index in plasma and breast muscle when half or all of the LA were substituted with LO in chickens ( $2 \% \mathrm{LA}+2 \% \mathrm{LO}$ or $4 \% \mathrm{LO}$ v. $4 \% \mathrm{LA})$. The plasma content of T-SOD in birds given 4\% LO with SI was higher $(P<0.05)$ than in birds given LO without SI. There were no 
Gou, Cui, Li, Fan, Lin, Wang, Jiang and Jiang

Table 3 Effects of dietary linseed oil supplementation, with and without soybean isoflavone, on growth performance of yellow-feathered chickens from 29 to 66 days of age ${ }^{1}$

\begin{tabular}{lcccccccccc}
\hline \hline & & & & & & \multicolumn{3}{c}{$P$ values $^{2}$} \\
\cline { 7 - 11 } Variable & $4 \%$ LA & $2 \%$ LA $+2 \%$ LO & $4 \%$ LO & $2 \%$ LA $+2 \%$ LO + SI & $4 \%$ LO + SI & SEM & Treatment & LO & SI & LO $\times$ SI \\
\hline Final BW (g) & 1828 & 1804 & 1838 & 1804 & 1801 & 6.530 & 0.27 & 0.27 & 0.19 & 0.20 \\
ADFI (g) & $92.07^{\mathrm{a}}$ & $88.23^{\mathrm{b}}$ & $88.82^{\mathrm{b}}$ & $88.18^{\mathrm{b}}$ & $87.58^{\mathrm{b}}$ & 0.467 & 0.010 & 0.99 & 0.41 & 0.45 \\
ADG (g) & 32.40 & 31.77 & 32.65 & 31.77 & 31.67 & 0.180 & 0.31 & 0.31 & 0.21 & 0.21 \\
Feed/gain (g/g) & $2.85^{\mathrm{a}}$ & $2.78^{\mathrm{ab}}$ & $2.72^{\mathrm{b}}$ & $2.78^{\mathrm{ab}}$ & $2.77^{\mathrm{ab}}$ & 0.013 & 0.045 & 0.20 & 0.47 & 0.36 \\
Survival rate (\%) & 98.34 & 98.89 & 98.89 & 97.22 & 98.89 & 0.383 & 0.61 & 0.58 & 0.78 & 0.46 \\
\hline \hline
\end{tabular}

$\mathrm{LA}=$ lard; $\mathrm{LO}=$ linseed oil; $\mathrm{SI}=30 \mathrm{mg} / \mathrm{kg}$ soybean isoflavone; $\mathrm{BW}=$ body weight; $\mathrm{ADG}=$ average daily gain; $\mathrm{ADFI}=$ average daily feed intake.

${ }^{1}$ Data are means for $n=6$ replicates (30 birds/replicate).

${ }^{2}$ Treatment, all five diets. LO, dietary linseed oil substituted for half or total LA in the last four diets. SI, dietary LO with or without SI in the last four diets.

a,b Means marked with different letters in rows differ significantly at $P<0.05$.

Table 4 Effects of dietary linseed oil supplementation, with and without soybean isoflavone, on lipid metabolism and antioxidation indicators of yellow-feathered chickens ${ }^{1}$

\begin{tabular}{|c|c|c|c|c|c|c|c|c|c|c|}
\hline \multirow[b]{2}{*}{ Variable } & \multirow[b]{2}{*}{$4 \%$ LA } & \multirow[b]{2}{*}{$2 \% \mathrm{LA}+2 \% \mathrm{LO}$} & \multirow[b]{2}{*}{$4 \%$ LO } & \multirow[b]{2}{*}{$2 \% \mathrm{LA}+2 \% \mathrm{LO}+\mathrm{SI}$} & \multirow[b]{2}{*}{$4 \% \mathrm{LO}+\mathrm{SI}$} & \multirow[b]{2}{*}{ SEM } & \multicolumn{4}{|c|}{$P$ values ${ }^{2}$} \\
\hline & & & & & & & Treatment & LO & SI & $\mathrm{LO} \times \mathrm{SI}$ \\
\hline \multicolumn{11}{|l|}{ Plasma } \\
\hline $\mathrm{TG}(\mathrm{mmol} / \mathrm{l})$ & $0.802^{\mathrm{a}}$ & $0.622^{b}$ & $0.490^{c}$ & $0.496^{c}$ & $0.379^{d}$ & 0.029 & 0.001 & 0.001 & 0.001 & 0.73 \\
\hline $\mathrm{TCH}(\mathrm{mmol} / \mathrm{l})$ & $2.73^{a}$ & $2.56^{\mathrm{ab}}$ & $2.38^{\mathrm{b}}$ & $2.30^{\mathrm{b}}$ & $1.66^{c}$ & 0.079 & 0.001 & 0.001 & 0.001 & 0.023 \\
\hline $\mathrm{HDL}-\mathrm{C}(\mathrm{mmol} / \mathrm{l})$ & 2.10 & 2.00 & 2.04 & 2.06 & 1.89 & 0.028 & 0.16 & 0.23 & 0.48 & 0.077 \\
\hline LDL-C (mmol/l) & 0.444 & 0.405 & 0.422 & 0.360 & 0.389 & 0.016 & 0.55 & 0.55 & 0.87 & 0.54 \\
\hline $\mathrm{T}-\mathrm{AOC}(\mathrm{U} / \mathrm{ml})$ & 6.43 & 7.13 & 7.07 & 7.80 & 7.17 & 0.181 & 0.22 & 0.38 & 0.36 & 0.50 \\
\hline T-SOD (U/ml) & $265.11^{a b}$ & $258.19^{b}$ & $242.63^{b}$ & $276.97^{a b}$ & $296.80^{\mathrm{a}}$ & 5.939 & 0.038 & 0.85 & 0.004 & 0.13 \\
\hline $\mathrm{GSH}(\mathrm{mg} / \mathrm{l})$ & 9.13 & 9.16 & 8.78 & 10.03 & 9.36 & 0.181 & 0.28 & 0.19 & 0.077 & 0.71 \\
\hline GSSG $(\mu \mathrm{mol} / \mathrm{l})$ & 12.57 & 13.13 & 11.80 & 10.89 & 10.34 & 0.405 & 0.16 & 0.17 & 0.012 & 0.57 \\
\hline GSH/GSSG & $0.770^{\mathrm{ab}}$ & $0.713^{b}$ & $0.747^{b}$ & $0.922^{a}$ & $0.912^{\mathrm{a}}$ & 0.028 & 0.027 & 0.75 & 0.001 & 0.55 \\
\hline MDA (nmol/ml) & $2.48^{\mathrm{a}}$ & $2.46^{\mathrm{a}}$ & $2.34^{\mathrm{a}}$ & $1.93^{b}$ & $2.01^{b}$ & 0.038 & 0.045 & 0.83 & 0.012 & 0.83 \\
\hline \multicolumn{11}{|l|}{ Breast muscle } \\
\hline GSH (mg/g prot) & $5.50^{\mathrm{ab}}$ & $5.12^{b}$ & $5.02^{b}$ & $7.65^{\mathrm{a}}$ & $6.78^{\mathrm{a}}$ & 0.101 & 0.047 & 0.50 & 0.010 & 0.58 \\
\hline GSSG $(\mu \mathrm{mol} / \mathrm{l})$ & 17.21 & 17.42 & 17.33 & 16.67 & 17.02 & 0.398 & 0.089 & 0.27 & 0.065 & 0.67 \\
\hline GSH/GSSG & $0.322^{c}$ & $0.295^{c}$ & $0.290^{c}$ & $0.459^{a}$ & $0.403^{b}$ & 0.0112 & 0.034 & 0.15 & 0.001 & 0.23 \\
\hline MDA (nmol/mg prot) & $1.34^{\mathrm{ab}}$ & $1.41^{\mathrm{a}}$ & $1.42^{\mathrm{a}}$ & $1.10^{\mathrm{b}}$ & $1.24^{\mathrm{ab}}$ & 0.021 & 0.034 & 0.23 & 0.022 & 0.43 \\
\hline Abdominal fat (\%) & $2.88^{\mathrm{a}}$ & $2.67^{\mathrm{ab}}$ & $2.15^{b}$ & $2.39^{a b}$ & $2.23^{b}$ & 0.086 & 0.024 & 0.042 & 0.76 & 0.23 \\
\hline
\end{tabular}

$\mathrm{LA}=$ lard; $\mathrm{LO}=$ linseed oil; $\mathrm{SI}=30 \mathrm{mg} / \mathrm{kg}$ soybean isoflavone; $\mathrm{T}-\mathrm{AOC}=$ total antioxidant capacity; $\mathrm{T}-\mathrm{SOD}=$ total superoxide dismutase; GSH = reduced glutathione; GSSG = oxidized glutathione; MDA = malondialdehyde; TG = total triglyceride; $\mathrm{TCH}=$ total cholesterol; $\mathrm{HDL}-\mathrm{C}=$ high-density lipoprotein cholesterol; $\mathrm{LDL}-\mathrm{C}=$ lowdensity lipoprotein cholesterol.

${ }^{1}$ Data are means for $n=6$ replicates ( 2 birds/replicate).

${ }^{2}$ Treatment, all five diets. LO, dietary LO substituted for half or total LA in the last four diets. SI, dietary linseed oil with or without SI in the last four diets.

$a, b, c, d$ Means marked with different letters in rows differ significantly at $P<0.05(n=6)$.

significant effects of the five diets on the T-AOC, GSH and GSSG contents of plasma, but the GSH/GSSG ratio was increased when the $\mathrm{SI}$ was added to diets containing $\mathrm{LO}$ $(2 \% \mathrm{LA}+2 \% \mathrm{LO}+\mathrm{SI}$ or $4 \% \mathrm{LO}+\mathrm{SI}$ v. $2 \% \mathrm{LA}+2 \% \mathrm{LO}$ or $4 \% \mathrm{LO} ; P<0.05)$. Adding SI to the diets containing LO significantly increased GSH content and GSH/GSSG ratio in breast muscle and decreased the concentration of MDA in plasma and breast muscle compared to its absence.

Compared with the chickens fed the 4\% LA diet, the contents of TG and TCH decreased by dietary inclusion of $\mathrm{LO}$, and especially in the presence of $\mathrm{SI}$, where the levels of $\mathrm{TG}$ and TCH were further decreased $(P<0.05)$, as shown by significant interaction between substitution of LA with $L O$ and inclusion of $\mathrm{SI}$ on $\mathrm{TCH}$. There were no effects of diet on the plasma contents of HDL-C or LDL-C. Table 4 shows that the abdominal fat percentage was also significantly decreased in birds fed both diets with $4 \%$ LO or $4 \%$ LO + SI compared to birds fed $4 \%$ LA.

\section{Meat quality}

The objective indicators related to meat quality of breast muscle are shown in Table 5. There were no effects of partial or complete replacement of $\mathrm{LA}$ with $\mathrm{LO}$, with or without $\mathrm{SI}$, on drip loss, $\mathrm{pH}$, shear values, color attributes, or IMF content of the breast muscle. 
Impacts of dietary linseed oil on chicken meat

Table 5 Effects of dietary linseed oil supplementation, with and without soybean isoflavone, on meat quality attributes in the breast muscle of yellowfeathered chickens ${ }^{1}$

\begin{tabular}{|c|c|c|c|c|c|c|c|c|c|c|}
\hline \multirow[b]{2}{*}{ Meat quality indicators } & \multirow[b]{2}{*}{$4 \% \mathrm{LA}$} & \multirow[b]{2}{*}{$2 \% \mathrm{LA}+2 \% \mathrm{LO}$} & \multirow[b]{2}{*}{$4 \%$ LO } & \multirow[b]{2}{*}{$2 \% \mathrm{LA}+2 \% \mathrm{LO}+\mathrm{SI}$} & \multirow[b]{2}{*}{$4 \% \mathrm{LO}+\mathrm{SI}$} & \multirow[b]{2}{*}{ SEM } & \multicolumn{4}{|c|}{$P$ values } \\
\hline & & & & & & & Treatment & LO & $\mathrm{SI}$ & $\mathrm{LO} \times \mathrm{SI}$ \\
\hline \multicolumn{11}{|l|}{ Color } \\
\hline Lightness $\left(L^{*}\right)$ & 57.12 & 56.32 & 57.45 & 56.62 & 55.12 & 0.582 & 0.78 & 0.90 & 0.47 & 0.35 \\
\hline Redness $\left(a^{*}\right)$ & 14.15 & 14.55 & 14.28 & 13.83 & 14.95 & 0.256 & 0.73 & 0.51 & 0.97 & 0.29 \\
\hline Yellowness $\left(b^{*}\right)$ & 11.45 & 10.40 & 11.00 & 11.78 & 10.07 & 0.335 & 0.50 & 0.47 & 0.88 & 0.15 \\
\hline $\mathrm{pH}_{24 \mathrm{~h}}$ & 5.71 & 5.76 & 5.71 & 5.70 & 5.75 & 0.017 & 0.80 & 0.90 & 0.79 & 0.23 \\
\hline Drip loss (\%) & 3.48 & 3.71 & 3.79 & 3.51 & 3.83 & 0.115 & 0.84 & 0.95 & 0.35 & 0.75 \\
\hline Shear force $(\mathrm{N})$ & 35.58 & 38.67 & 39.40 & 35.38 & 36.28 & 1.075 & 0.70 & 0.63 & 0.41 & 0.45 \\
\hline IMF (\%) & 1.113 & 1.229 & 1.329 & 1.263 & 1.396 & 0.080 & 0.79 & 0.53 & 0.79 & 0.93 \\
\hline
\end{tabular}

$\mathrm{pH}_{24 \mathrm{~h}}=\mathrm{pH}$ 24-h postmortem, IMF = intramuscular fat (as percentage of dry muscle).

${ }^{1}$ Data are means for $n=6$ replicates (2 birds/replicate), dietary treatments were combinations of $\mathrm{LA}=$ lard; $\mathrm{LO}=$ linseed oil; and $\mathrm{SI}=30 \mathrm{mg} / \mathrm{kg}$ soybean isoflavone.

${ }^{2}$ Treatment, all five diets. LO, dietary LO substituted for half or total LA in the last four diets. SI, dietary linseed oil with or without SI in the last four diets.

Table 6 Effects of dietary linseed oil supplementation, with and without soybean isoflavone, on fatty acid composition of lipids in the breast muscle of yellow-feathered chickens

\begin{tabular}{|c|c|c|c|c|c|c|c|c|c|c|}
\hline \multirow[b]{2}{*}{ Fatty acid(\%) } & \multirow[b]{2}{*}{$4 \%$ LA } & \multirow[b]{2}{*}{$2 \% \mathrm{LA}+2 \% \mathrm{LO}$} & \multirow[b]{2}{*}{$4 \%$ LO } & \multirow[b]{2}{*}{$2 \% \mathrm{LA}+2 \% \mathrm{LO}+\mathrm{SI}$} & \multirow[b]{2}{*}{$4 \% \mathrm{LO}+\mathrm{SI}$} & \multirow[b]{2}{*}{ SEM } & \multicolumn{4}{|c|}{$P$ values $^{1}$} \\
\hline & & & & & & & Treatment & LO & $\mathrm{SI}$ & $\mathrm{LO} \times \mathrm{SI}$ \\
\hline $\mathrm{C} 14: 0$ & $0.672^{\mathrm{a}}$ & $0.618^{\mathrm{ab}}$ & $0.491^{c}$ & $0.586^{\mathrm{b}}$ & $0.492^{c}$ & 0.016 & 0.001 & 0.001 & 0.62 & 0.49 \\
\hline C16:0 & $25.70^{\mathrm{a}}$ & $22.53^{b c}$ & $21.73^{c}$ & $23.89^{\mathrm{b}}$ & $22.48^{\mathrm{bc}}$ & 0.332 & 0.001 & 0.053 & 0.064 & 0.58 \\
\hline C16:1n-7 & 3.15 & 3.33 & 2.53 & 2.64 & 2.51 & 0.128 & 0.12 & 0.13 & 0.24 & 0.27 \\
\hline C18:0 & 9.24 & 8.08 & 8.38 & 9.42 & 9.61 & 0.205 & 0.058 & 0.59 & 0.010 & 0.91 \\
\hline C18:1n-9 & $29.41^{a}$ & $29.14^{a}$ & $25.64^{b}$ & $27.80^{\mathrm{ab}}$ & $25.87^{b}$ & 0.486 & 0.019 & 0.012 & 0.58 & 0.44 \\
\hline C18:2n-6 & 20.77 & 22.27 & 20.98 & 20.30 & 18.96 & 0.368 & 0.063 & 0.12 & 0.022 & 0.97 \\
\hline C18:3n-3 & $0.919^{c}$ & $6.93^{b}$ & $12.55^{\mathrm{a}}$ & $5.78^{b}$ & $11.47^{\mathrm{a}}$ & 0.803 & 0.001 & 0.001 & 0.072 & 0.95 \\
\hline$C 20: 2 n-6$ & 0.334 & 0.282 & 0.278 & 0.316 & 0.306 & 0.011 & 0.51 & 0.79 & 0.26 & 0.92 \\
\hline$C 20: 3 n-6$ & 0.999 & 0.660 & 0.749 & 0.871 & 0.845 & 0.049 & 0.26 & 0.77 & 0.17 & 0.59 \\
\hline$C 20: 4 n-6$ & $5.487^{a}$ & $2.998^{b}$ & $2.671^{b}$ & $3.839^{b}$ & $3.459^{b}$ & 0.233 & 0.002 & 0.48 & 0.11 & 0.96 \\
\hline$C 20: 5 n-3$ & $0.432^{d}$ & $0.818^{c}$ & $1.358^{b}$ & $1.360^{\mathrm{b}}$ & $1.697^{\mathrm{a}}$ & 0.094 & 0.001 & 0.001 & 0.001 & 0.039 \\
\hline$C 22: 6 n-3$ & $0.926^{b}$ & $1.049^{b}$ & $1.076^{\mathrm{b}}$ & $1.292^{\mathrm{a}}$ & $1.317^{\mathrm{a}}$ & 0.047 & 0.009 & 0.48 & 0.026 & 0.52 \\
\hline $\mathrm{C} 24: 0$ & $1.189^{a}$ & $0.530^{\mathrm{bc}}$ & $0.442^{c}$ & $0.749^{b}$ & $0.620^{b c}$ & 0.059 & 0.001 & 0.12 & 0.095 & 0.87 \\
\hline SFA & $36.80^{\mathrm{a}}$ & $31.76^{c}$ & $31.04^{c}$ & $34.48^{\mathrm{b}}$ & $33.12^{b c}$ & 0.504 & 0.001 & 0.22 & 0.011 & 0.65 \\
\hline MUFA & $32.83^{a}$ & $32.75^{a}$ & $28.41^{\mathrm{b}}$ & $30.71^{\mathrm{ab}}$ & $28.54^{b}$ & 0.588 & 0.017 & 0.014 & 0.44 & 0.38 \\
\hline PUFA & $29.82^{c}$ & $34.77^{b}$ & $39.49^{a}$ & $33.63^{b}$ & $37.78^{a}$ & 0.729 & 0.001 & 0.001 & 0.16 & 0.77 \\
\hline PUFA/SFA & $0.811^{d}$ & $1.102^{b}$ & $1.274^{\mathrm{a}}$ & $0.975^{c}$ & $1.146^{\mathrm{b}}$ & 0.033 & 0.001 & 0.001 & 0.042 & 0.65 \\
\hline$n-3$ & $2.40^{c}$ & $8.68^{b}$ & $14.80^{\mathrm{a}}$ & $8.30^{b}$ & $14.35^{\mathrm{a}}$ & 0.864 & 0.001 & 0.001 & 0.37 & 0.93 \\
\hline$n-6$ & 27.42 & 26.10 & 24.68 & 25.33 & 23.43 & 0.453 & 0.054 & 0.11 & 0.32 & 0.81 \\
\hline$n-6 / n-3$ & $11.45^{a}$ & $3.03^{b}$ & $1.68^{c}$ & $3.11^{b}$ & $1.65^{c}$ & 0.687 & 0.001 & 0.001 & 0.87 & 0.74 \\
\hline
\end{tabular}

$\mathrm{LA}=$ lard; $\mathrm{LO}=$ linseed oil; $\mathrm{SI}=30 \mathrm{mg} / \mathrm{kg}$ soybean isoflavone; SFA = saturated fatty acids; MUFA = monounsaturated fatty acids; PUFA = polyunsaturated fatty acids.

${ }^{1}$ Treatment, all five diets. LO, dietary LO substituted for half or total LA in the last four diets. SI, dietary linseed oil with or without SI in the last four diets.

$\mathrm{a}, \mathrm{b}, \mathrm{c}, \mathrm{d}$ Means marked with different letters in rows differ significantly at $P<0.05(n=6)$.

\section{Muscle fatty acids}

The fatty acid composition of the total lipids in chicken breast muscle is provided in Table 6 . Chickens fed diets containing LO exhibited higher contents $(P<0.05)$ of ALA, EPA, n-3, PUFA and PUFA/SFA, together with lower contents $(P<0.05)$ of palmitate $(C 16: 0)$, arachidonate $(C 20: 4 n-6)$, lignoceric acid (C24:0), SFA and n-6:n-3 ratio compared with the $4 \%$ LA diet. The myristate $(\mathrm{C} 14: 0)$, oleate $(\mathrm{C} 18: 1 \mathrm{n}-9)$ and MUFA contents were lower $(P<0.05)$ in chickens fed diets with $4 \% \mathrm{LO}$ or $4 \% \mathrm{LO}+\mathrm{SI}$ than in those fed the basal diet with $\mathrm{LA}$ alone. When $30 \mathrm{mg} \mathrm{SI} / \mathrm{kg}$ was added to the diets containing LO, the EPA and DHA contents increased further $(P<0.05)$. In the case of EPA, a significant interaction existed between $\mathrm{LO}$ level and inclusion of $\mathrm{SI}$.

Lipid-related health indicators ( $\mathrm{Al}, \mathrm{TI}$ and $\mathrm{h}: \mathrm{H}$ ) of breast muscle samples were calculated from the fatty acid compositions (Figure 1). The Al and TI indicators showed similar significant decreases with increased inclusion of $\mathrm{LO}$; changes in the $\mathrm{h}: \mathrm{H}$ index were in the opposite direction. Inclusion of $\mathrm{SI}$ had no effect on lipid-related health indicators. 


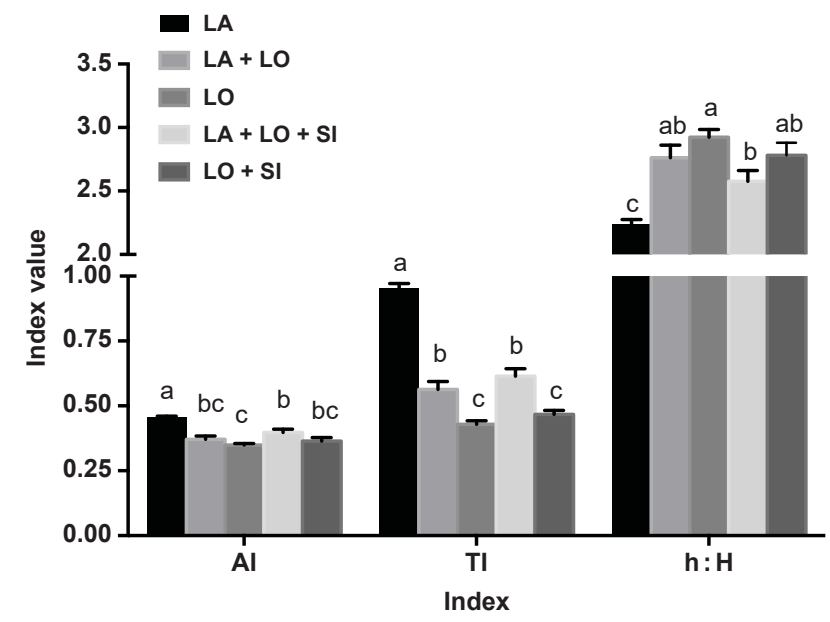

Figure 1 Effects of dietary linseed oil supplementation, with or without soybean isoflavone, on lipid-related health indicators in chicken breast muscle. $\mathrm{Al}=$ atherogenic index; $\mathrm{Tl}=$ thrombogenic index; $\mathrm{h}: \mathrm{H}=$ hypocholesterolemic/hypercholesterolemic; LA = lard; LO = linseed oil; $\mathrm{SI}=30 \mathrm{mg} / \mathrm{kg}$ soybean isoflavone. Values with different letters (a to c) within a variable (Al, $\mathrm{TI}$ and $\mathrm{h}: \mathrm{H}$ ) indicate significant differences between experimental diets $(P<0.05)$. Error bars indicate standard error of each diet $(n=6)$.

Muscle expression of genes related to lipid metabolism As shown in Table 7, the relative transcript abundance of FADS1, FADS2 and ELOVL5 in breast muscle significantly increased with $4 \% \mathrm{LO}, 2 \% \mathrm{LA}+2 \% \mathrm{LO}+\mathrm{SI}$ and $4 \%$ $\mathrm{LO}+\mathrm{SI}$ diets compared with the $4 \% \mathrm{LA}$ diet, and the $2 \%$ $\mathrm{LA}+2 \% \mathrm{LO}$ diet being intermediate. Adding SI to the LO diets of birds increased the gene expression of FADS2 and ELOVL2 in breast muscle compared to its absence. The transcript abundance of $L P L$ increased significantly with LO substitution (2\% LA + 2\% LO and 4\% LO v. 4\% LA), HMGCR by $2 \% \mathrm{LA}+2 \% \mathrm{LO}$ and $4 \% \mathrm{LO}+\mathrm{SI}$, and CPT1 $\alpha$ by all diets containing $\mathrm{LO}$, with or without $\mathrm{SI}$; there were no significant effects of diet on FAS and SREBP-1 transcripts.

\section{Discussion}

Animal fats and vegetable oils are often used to increase the dietary energy density to meet the requirements of fast-growing chickens. Additionally, there is an increasing demand for functional foods, whereby supplementation with LO (rich in ALA) is becoming an accepted practice to ensure a favorable fatty acid composition of meat. In this experiment with an improved, local breed of chicken, partially or totally replacing dietary LA with LO decreased the ADFI and increased the feed efficiency. These findings agree with the previous work, showing that chickens' growth performance responds differently to animal or vegetable lipids. For instance, chickens fed diets containing fish oil combined with LO have decreased the feed intake than those fed diets with fish oil combined with LA (Konieczka et al., 2017). Ferrini et al. (2008) also reported that broiler chickens fed diets with LO had decreased feed intake and improved feed efficiency compared with those fed tallow. The effect of the type of fat on feed efficiency could be related to the degree of unsaturation, because some authors (Zollitsch et al., 1997; Duran-Montgé et al., 2007) have reported that digestibility of fat increases as the degree of unsaturation increases. It is evident here that substituting $2 \%$ or $4 \%$ LO for an equivalent amount of $L A$ in the chicken diet improved the feed efficiency. In addition, in the present study, SI had no effect on chickens' growth performance.

Compared to saturated fats, dietary fats rich in n-3 PUFA increased the susceptibility of chickens to oxidation. In the present study, when the dietary LA was substituted with $L O$, there were no significant differences in the T-SOD activity, T-AOC, GSH, GSSH and MDA contents in plasma and breast muscle. When $30 \mathrm{mg} \mathrm{SI} / \mathrm{kg}$ was also added to the diet, the plasma T-SOD activity and muscle GSH contents increased and the MDA content in plasma and breast muscle decreased. A previous study showed that the addition of 40 or $80 \mathrm{mg} / \mathrm{kg}$ of SI significantly increased T-AOC and slightly

Table 7 Effects of dietary linseed oil supplementation, with and without soybean isoflavone, on expression of genes related to lipid metabolism of breast muscle in yellow-feathered chickens

\begin{tabular}{|c|c|c|c|c|c|c|c|c|c|c|}
\hline \multirow[b]{2}{*}{ Genes } & \multirow[b]{2}{*}{$4 \%$ LA } & \multirow[b]{2}{*}{$2 \% \mathrm{LA}+2 \% \mathrm{LO}$} & \multirow[b]{2}{*}{$4 \%$ LO } & \multirow[b]{2}{*}{$2 \% \mathrm{LA}+2 \% \mathrm{LO}+\mathrm{SI}$} & \multirow[b]{2}{*}{$4 \% \mathrm{LO}+\mathrm{SI}$} & \multirow[b]{2}{*}{ SEM } & \multicolumn{4}{|c|}{$P$ values ${ }^{1}$} \\
\hline & & & & & & & Treatment & LO & SI & $\mathrm{LO} \times \mathrm{SI}$ \\
\hline FADS1 & $1.03^{b}$ & $1.15^{\mathrm{ab}}$ & $1.30^{\mathrm{a}}$ & $1.37^{\mathrm{a}}$ & $1.30^{\mathrm{a}}$ & 0.040 & 0.038 & 0.16 & 0.61 & 0.14 \\
\hline FADS2 & $1.04^{c}$ & $1.32^{\mathrm{bc}}$ & $1.51^{b}$ & $1.73^{\mathrm{a}}$ & $1.79^{a}$ & 0.050 & 0.013 & 0.12 & 0.026 & 0.21 \\
\hline ELOVL2 & $1.06^{b}$ & $1.15^{b}$ & $1.23^{\mathrm{ab}}$ & $1.98^{\mathrm{a}}$ & $2.03^{a}$ & 0.111 & 0.011 & 0.16 & 0.053 & 0.28 \\
\hline ELOVL5 & $1.05^{b}$ & $1.41^{\mathrm{ab}}$ & $1.59^{a}$ & $1.62^{\mathrm{a}}$ & $1.68^{a}$ & 0.068 & 0.015 & 0.43 & 0.39 & 0.47 \\
\hline FAS & 1.04 & 0.88 & 0.98 & 0.75 & 0.82 & 0.039 & 0.11 & 0.32 & 0.067 & 0.85 \\
\hline$L P L$ & $1.02^{c}$ & $1.40^{\mathrm{a}}$ & $1.34^{\mathrm{ab}}$ & $1.10^{\mathrm{bc}}$ & $1.17^{\mathrm{abc}}$ & 0.047 & 0.044 & 0.94 & 0.043 & 0.52 \\
\hline$H M G C R$ & $1.03^{b}$ & $1.29^{\mathrm{a}}$ & $1.22^{\mathrm{ab}}$ & $1.11^{\mathrm{ab}}$ & $1.31^{\mathrm{a}}$ & 0.035 & 0.019 & 0.35 & 0.60 & 0.060 \\
\hline 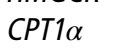 & $1.03^{b}$ & $2.74^{\mathrm{a}}$ & $2.18^{\mathrm{a}}$ & $2.31^{\mathrm{a}}$ & $2.20^{\mathrm{a}}$ & 0.158 & 0.007 & 0.28 & 0.55 & 0.46 \\
\hline SREBP-1 & 1.02 & 1.28 & 0.98 & 1.26 & 1.28 & 0.065 & 0.39 & 0.50 & 0.30 & 0.35 \\
\hline
\end{tabular}

$\mathrm{LA}=$ lard; $\mathrm{LO}=$ linseed oil; $\mathrm{SI}=30 \mathrm{mg} / \mathrm{kg}$ soybean isoflavone; $F A D S 1=$ Fatty acid desaturase $1 ; F A D S 2=$ Fatty acid desaturase 2; ELOVL2= fatty acid elongase 2; $E L O V L 5=$ fatty acid elongase $5 ; \quad F A S=$ fatty acid synthase; $L P L=$ lipoprotein lipase; $H M G C R=3$-hydroxy-3-methylglutaryl-coenzyme $A$ reductase; $C P T 1 \alpha=$ carnitine palmitoyltransferase- $1 \alpha ; S R E B P-1=$ sterol regulatory element binding protein-1.

${ }^{1}$ Treatment, all five diets. LO, dietary LO substituted for half or total LA in the last four diets. SI, dietary linseed oil with or without SI in the last four diets.

$a, b, c$ Means marked with different letters in rows differ significantly at $P<0.05(n=6)$. 
elevated T-SOD activity in the plasma of chickens (Jiang et al., 2007b). Dietary SI at 20 and $40 \mathrm{mg} / \mathrm{kg}$ levels enhanced T-SOD activity in chicken meat (Jiang et al., 2014). These findings suggest that supplemental SI would be expected to improve the antioxidative status of chickens.

The present results showed that diets with LO decreased the plasma TG and TCH contents in chickens compared with those fed the diet with $L A$, with greater decreases when $\mathrm{SI}$ was added. This observation is consistent with the finding that diets enriched with n-3 PUFA from LO and fish oil clearly decreased the serum TCH and TG in broiler chickens (Ibrahim et al., 2018). The results explain the decreased abdominal fat found here in chickens given dietary LO. Previous experiments have shown lower abdominal fat deposition in broilers fed dietary LO compared with those fed tallow (Crespo and Esteve-Garcia, 2001; Ferrini et al., 2008).

The current data confirmed earlier work (López-Ferrer et al., 2001; Bou et al., 2005) that dietary LO had no effects on objective indicators of meat quality and IMF content of breast muscle in chickens. Consistent with the earlier work (López-Ferrer et al., 2001), dietary LO had a large impact on fatty acid composition in chicken breast muscle in the present study, resulting in more n-3 PUFA (ALA, EPA, and DHA) with less SFA and MUFA. The interesting additional finding here was that adding $\mathrm{SI}$ to the LO diet further increased the deposition of EPA and DHA in breast muscle, presumably because of the antioxidant property of the isoflavone. This interpretation is consistent with the effects of other antioxidant additives; Pappas et al. (2012) found that breast muscle contents of long-chain PUFA (C20:3n-6, C20:4n-6, EPA, DHA and docosapentaenoic acid (22:5n-3; DPA)) increased linearly with dietary inclusion of selenium $(0.15,0.3$ and $3 \mathrm{mg} / \mathrm{kg})$ in chickens. Haug et al. (2007) similarly found that high dietary selenium increased the contents of the long-chain n-3 PUFA (EPA, DPA and DHA) in broiler meat from the intake of plant oils containing n-3 PUFA.

The present study has also found that dietary LO substituted for half or all of the LA significantly reduced Al and TI and increased $\mathrm{h}: \mathrm{H}$ in the chicken meat. Accordingly, a lower $\mathrm{Al}$ and higher $\mathrm{h}: \mathrm{H}$ ratio and $\mathrm{n}-3$ content of meat from LOsupplemented chickens compared with LA have been recently reported (Milankovic et al., 2019). Lower values of $\mathrm{Al}$ and $\mathrm{TI}$ indicate a healthier ratio with regard to fatty acids that reduce platelet aggregation and the potential for coronary diseases; conversely, a higher $\mathrm{h}: \mathrm{H}$ fatty acid ratio indicates a more nutritionally suitable fatty acid profile (Omri et al., 2019). These results indicate that dietary supplementation with LO plus SI has a positive effect on the nutritional value of chicken meat, expected to be beneficial for human health from its increased content of n-3 PUFA.

Chicken meat has the potential to be a sustainable source of ALA, EPA and DHA as chickens are capable of synthesizing these longer n-3 PUFA from dietary-derived ALA (Gregory and James, 2014). In the present study, the muscle expression of several relevant genes (FADS1, FADS2, ELOVL2 and ELOVL5) was generally increased by dietary LO with SI supplementation in the birds. To a certain extent, these findings were similar to that found earlier. Jing et al. (2013) found that hepatic gene expression of desaturase and elongase (FADS1, FADS2, ELOVL2 and ELOVL5) increased as the dietary ratio of 18:2n-6 (LA)/ALA progressively declined; expression was highest in birds fed lower LA/ALA diets. The present results indicate that intake of dietary $\mathrm{LO}$ with $\mathrm{SI}$ in chickens resulted in the synthesis of n-3 PUFA in breast muscle by regulating the expression of these relevant genes.

In conclusion, dietary replacement of half or all LA with LO increased feed efficiency and markedly enriched the meat of chickens with n-3 PUFA (ALA, EPA and DHA); it also notably improved lipid-related health indicators (lower $\mathrm{Al}, \mathrm{TI}$ and higher $\mathrm{h}: \mathrm{H}$ ratio) and decreased lipid-related indicators (plasma TG, TCH; abdominal fat percentage) without adverse effect on the meat quality. Adding the antioxidant SI to the LO diets further increased the muscle contents of EPA and DHA, decreased the plasma TG and TCH levels and improved the antioxidative status of chickens. Interactions were detected between substitution of LA with LO and inclusion of SI on EPA and TCH contents. Inclusion of LO with SI in the chicken's diet increased the muscle expression of genes related to lipid metabolism, viz., FADS1, FADS2, ELOVL2 and ELOVL5. These results indicate that diets supplemented with LO can effectively improve the nutritional value of chicken meat, and this was even better when LO was given together with SI.

\section{Acknowledgements}

The authors sincerely thank W. Bruce Currie (Emeritus Professor, Cornell University, Ithaca, NY, USA) for his help in presentation of this manuscript. This study was supported by National Key R\&D Project (2018YFD0500600), Earmarked Fund for Modern Agro-industry Technology Research System (CARS-41-G10) from Ministry of Agriculture and Rural Affairs, the Natural Science Foundation from Guangdong province (2017A030310096), the National Natural Science Foundation (31802104), the Scientific and Technological Project of Guangdong Province (2017B020202003, 2019A050505007), the Scientific and Technological Project of Guangzhou city (201804020091), the Outstanding Talents Training Program of Guangdong Academy of Agricultural Sciences, Supporting Program for Guangdong Agricultural Research \& Development Center of Livestock and Poultry Healthy Breeding, Supporting Program for Transformation of Scientific and Technological Achievements and Technology Extension Service of Animal Husbandry and Aquatic Industry in Meizhou Region (2018063005), the Scientific and Technological Project of Guangdong Academy of Agricultural Sciences (201601TD) and the Presidential Foundation of the Guangdong Academy of Agricultural Sciences (201620, 201805, 201807B, 201809B, 201908), China.

(1) X. Y. Cui 0000-0003-0669-5790

\section{Declaration of interest}

The authors declare that there are no conflicts of interest. 


\section{Ethics statement}

All experimental procedures conformed to guidelines established by the Guangdong Academy of Agricultural Sciences (Guangzhou, China) Institutional Animal Care and Use Committee.

\section{Software and data repository resources}

The authors declare that the data of this research are not deposited in any official repository.

\section{Supplementary material}

To view supplementary material for this article, please visit https://doi.org/10.1017/S1751731120001020

\section{References}

Bou R, Guardiola F, Barroeta AC and Codony R 2005. Effect of dietary fat sources and zinc and selenium supplements on the composition and consumer acceptability of chicken meat. Poultry Science 84, 1129-1140.

Crespo $\mathrm{N}$ and Esteve-Garcia E 2001. Dietary fatty acid profile modifies abdominal fat deposition in broiler chickens. Poultry Science 80, 71-78.

Duran-Montgé P, Lizardo R, Torrallardona D and Esteve-Garcia E 2007. Fat and fatty acid digestibility of different fat sources in growing pigs. Livestock Science 109, 66-69.

Fernández M, Ordóñez JA, Cambero I, Santos C, Pin C and de la Hoz L 2007. Fatty acid compositions of selected varieties of Spanish dry ham related to their nutritional implications. Food Chemistry 101, 107-112.

Ferrini G, Baucells MD, Esteve-García E and Barroeta AC 2008. Dietary polyunsaturated fat reduces skin fat as well as abdominal fat in broiler chickens. Poultry Science 87, 528-535.

Gregory MK and James MJ 2014. Functional characterization of the duck and turkey fatty acyl elongase enzymes ELOVL5 and ELOVL2. Journal of Nutrition 144, 1234-1239.

Haug A, Eich-Greatorex S, Bernhoft A, Wold JP, Hetland H, Christophersen OA and Sogn $T$ 2007. Effect of dietary selenium and omega-3 fatty acids on muscle composition and quality in broilers. Lipids in Health \& Disease 6, 1-9.

Ibrahim D, El-Sayed R, Khater SI, Said EN and El-Mandrawy SA 2018. Changing dietary n-6: $n-3$ ratio using different oil sources affects performance, behavior, cytokines mRNA expression and meat fatty acid profile of broiler chickens. Animal Nutrition 4, 44-51.

Jiang SQ, Jiang ZY, Zhou GL, Lin YC and Zheng CT 2014. Effects of dietary isoflavone supplementation on meat quality and oxidative stability during storage in Lingnan yellow broilers. Journal of Integrative Agriculture 13, 387-393.

Jiang SQ, Jiang ZY, Wu TX, Ma XY, Zheng CT and Zou ST 2007a. Protective effects of a synthetic soybean isoflavone against oxidative damage in chick skeletal muscle cells. Food Chemistry 105, 1086-1090.

Jiang ZY, Jiang SQ, Lin YC, Xi PB, Yu DQ and Wu TX 2007b. Effects of soybean isoflavone on growth performance, meat quality, and antioxidation in male broilers. Poultry Science 86, 1356-1362.
Jing M, Gakhar N, Gibson RA and House JD 2013. Dietary and ontogenic regulation of fatty acid desaturase and elongase expression in broiler chickens. Prostaglandins Leukotrienes \& Essential Fatty Acids 89, 107-113.

Kartikasari LR, Hughes RJ, Geier MS, Makrides M and Gibson RA 2012. Dietary alpha-linolenic acid enhances omega-3 long chain polyunsaturated fatty acid levels in chicken tissues. Prostaglandins Leukotrienes \& Essential Fatty Acids 87, 103-109.

Konieczka P, Czauderna M and Smulikowska S 2017. The enrichment of chicken meat with omega-3 fatty acids by dietary fish oil or its mixture with rapeseed or flaxseed-effect of feeding duration: dietary fish oil, flaxseed, and rapeseed and $n-3$ enriched broiler meat. Animal Feed Science and Technology 223, 42-52.

Kouba $\mathrm{M}$ and Mourot J 2011. A review of nutritional effects on fat composition of animal products with special emphasis on $n-3$ polyunsaturated fatty acids. Biochimie 93, 13-17.

Liu J, Chang SK and Wiesenborn D 2005. Antioxidant properties of soybean isoflavone extract and tofu in vitro and in vivo. Journal of Agricultural and Food Chemistry 53, 2333-2340.

López-Ferrer S, Baucells MD, Barroeta AC, Galobart J and Grashorn MA 2001. $\mathrm{n}$-3 Enrichment of chicken meat. 2. Use of precursors of long-chain polyunsaturated fatty acids: linseed oil. Poultry Science 80, 753-761.

Milankovic B, Ćiric J, Krstic M, Starcevic M, Baltic B, Šefer D, Đordevoc V, Popovic M and Markovic R 2019. Effect of dietary fatty acid pattern on growth performance, carcass characteristics, fatty acid profile, and serum biochemistry parameters in broiler chickens. Kafkas Universitesi Veteriner Fakultesi Dergisi 25, 507-516.

Omri B, Chalghoumi R, Izzo L, Ritieni A, Lucarini M, Durazzo A, Abdouli H and Santini A 2019. Effect of dietary incorporation of linseed alone or together with tomato-red pepper mix on laying hens' egg yolk fatty acids profile and health lipid indexes. Nutrients 11, 813.

Pappas AC, Zoidis E, Papadomichelakis G and Fegeros K 2012. Supranutritional selenium level affects fatty acid composition and oxidative stability of chicken breast muscle tissue. Journal of Animal Physiology and Animal Nutrition 96, 385-394.

Rasmussen AJ and Andersson M 1996. New method for determination of drip loss in pork muscles. In Proceedings of the 42nd International Congress of Meat Science and Technology, Lillehammer, Norway, pp. 286-287.

Riediger ND, Othman RA, Suh M and Moghadasian MH 2009. A systemic review of the roles of $n-3$ fatty acids in health and disease. Journal of the American Dietetic Association 109, 668-679.

Ruxton C, Reed S, Simpson M and Millington K 2007. The health benefits of omega-3 polyunsaturated fatty acids: a review of the evidence. Journal of Human Nutrition and Dietetics 20, 275-285.

Rymer C and Givens DI 2005. n-3 fatty acid enrichment of edible tissue of poultry: a review. Lipids 40, 121-130.

Setchell KD 1998. Phytoestrogens: the biochemistry, physiology, and implications for human health of soy isoflavones. American Journal of Clinical Nutrition 68, 1333S-1346S.

Ulbricht T and Southgate D 1991. Coronary heart disease: seven dietary factors. Lancet 338, 985-992.

Zollitsch W, Knaus W, Aichinger F and Lettner F 1997. Effects of different dietary fat sources on performance and carcass characteristics of broilers. Animal Feed Science \& Technology $66,63-73$. 